\title{
Corrigendum to "Evaluation and Management of Skeletal Health in Celiac Disease: Position Statement"
}

\author{
Mona A. Fouda, ${ }^{1}$ Aliya A. Khan, ${ }^{2}$ Muhammad Sultan, ${ }^{3}$ Lorena P. Rios, ${ }^{2}$ \\ Karen McAssey, ${ }^{4}$ and David Armstrong ${ }^{2,5}$ \\ ${ }^{1}$ College of Medicine, King Saud University, Riyadh, Saudi Arabia \\ ${ }^{2}$ Department of Medicine, McMaster University, Hamilton, ON, Canada \\ ${ }^{3}$ Michael G. DeGroote School of Medicine, McMaster University, Hamilton, ON, Canada \\ ${ }^{4}$ Department of Pediatrics, McMaster University, Hamilton, ON, Canada \\ ${ }^{5}$ Division of Gastroenterology, McMaster University, Hamilton, ON, Canada \\ Correspondence should be addressed to Aliya A. Khan; draliyakhan@gmail.com
}

Received 14 May 2017; Accepted 22 May 2017; Published 2 July 2017

Copyright (c) 2017 Mona A. Fouda et al. This is an open access article distributed under the Creative Commons Attribution License, which permits unrestricted use, distribution, and reproduction in any medium, provided the original work is properly cited.

In the article titled "Evaluation and Management of Skeletal Health in Celiac Disease: Position Statement" [1], there was an error regarding the FRAX ${ }^{\circledR}$ tool, which should be clarified as follows.

The article notes: "The WHO has developed an absolute fracture risk assessment tool ('FRAX') to estimate the 10-year fracture risk in all adults, which is based on the integration of femoral neck bone density, age and other important clinical risk factors [66]." However, the World Health Organization (WHO) did not develop, test, or endorse the FRAX tool or its recommendations [2]. The metabolic bone disease unit at the University of Sheffield that developed FRAX was a WHO Collaborating Centre from 1991 to 2010. Treatment guidelines must undergo a formal process before they can be endorsed by the WHO.

\section{References}

[1] M. A. Fouda, A. A. Khan, M. Sultan, L. P. Rios, K. McAssey, and D. Armstrong, "Evaluation and management of skeletal health in celiac disease: position statement," Canadian Journal of Gastroenterology, vol. 26, no. 11, pp. 819-829, 2012.

[2] N. Ford, S. L. Norris, and S. R. Hill, “Clarifying WHO's position on the FRAX ${ }^{\circledR}$ tool for fracture prediction," Bulletin of the World Health Organization, vol. 94, no. 12, article 862, 2016. 


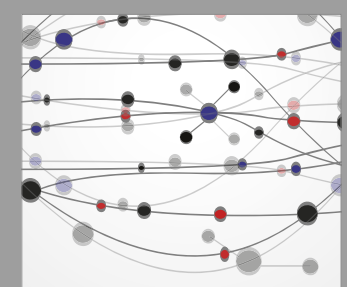

The Scientific World Journal
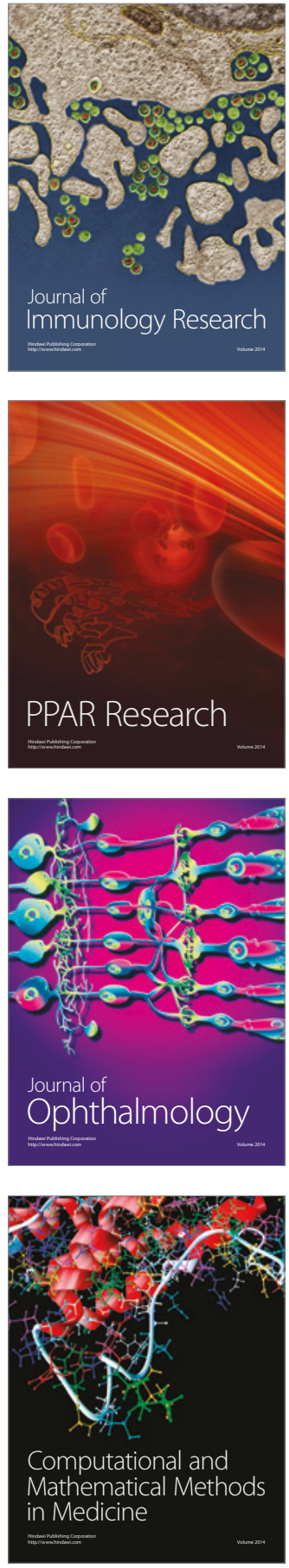

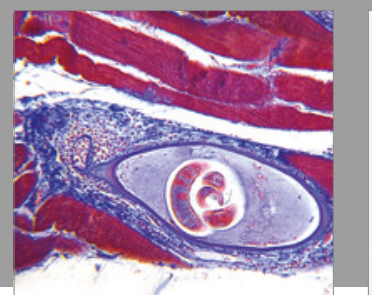

Gastroenterology Research and Practice
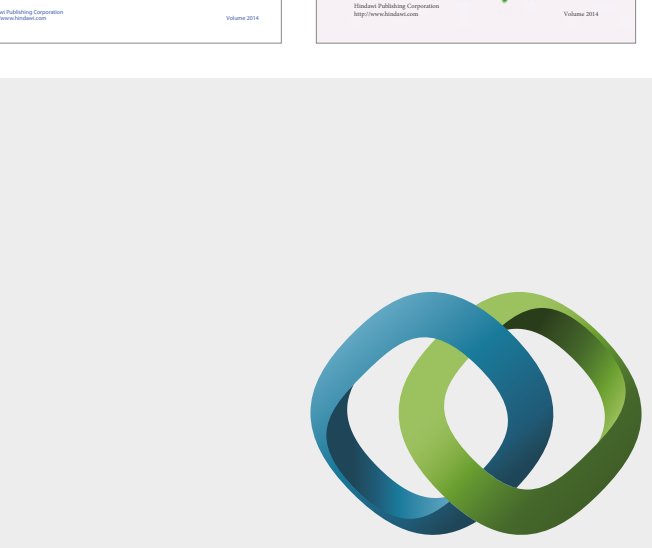

\section{Hindawi}

Submit your manuscripts at

https://www.hindawi.com
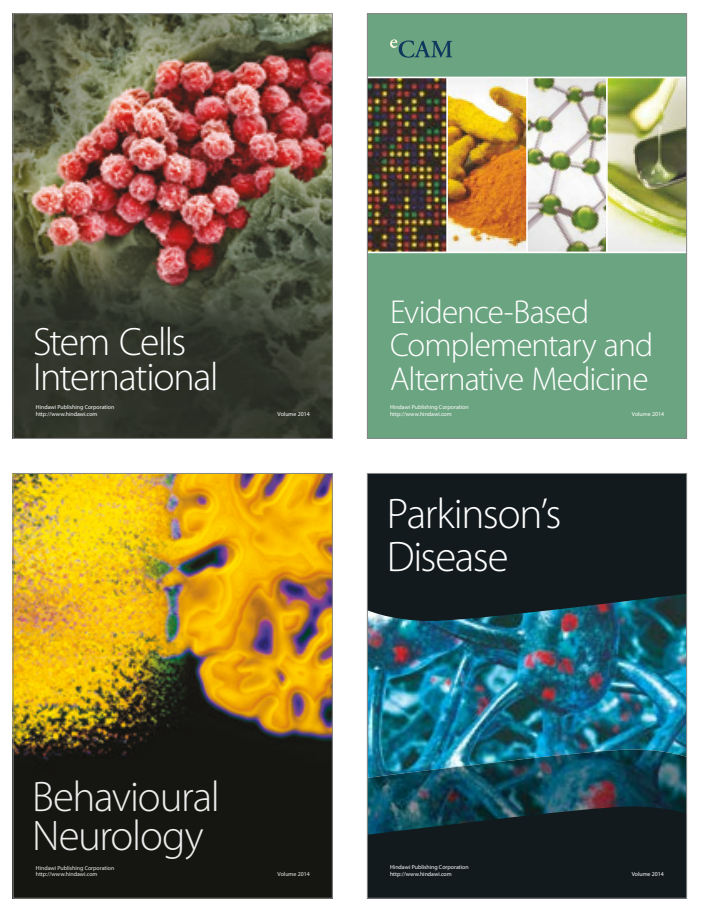
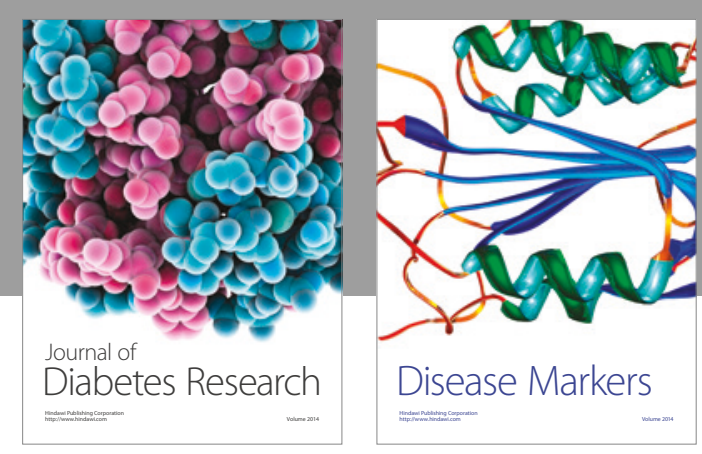

Disease Markers
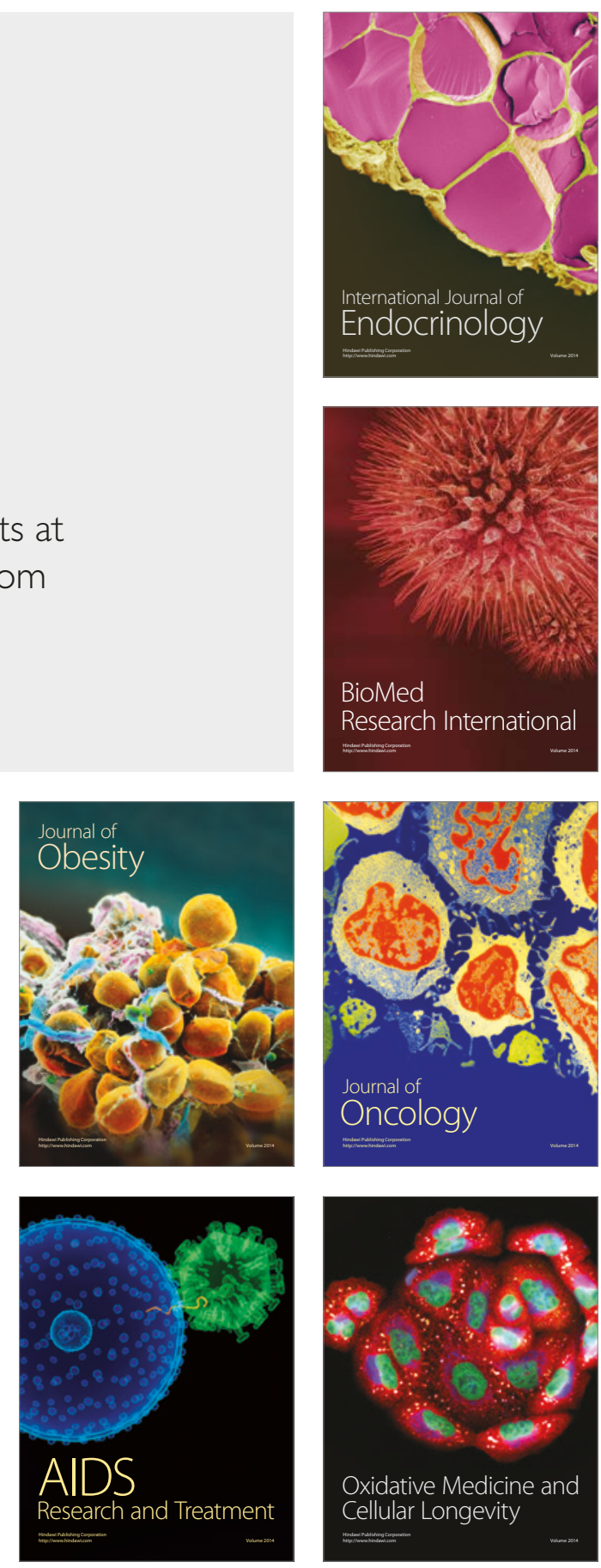